\title{
Rhodacyanine Analog MKT-077
}

National Cancer Institute

\section{Source}

National Cancer Institute. Rhodacyanine Analog MKT-077. NCI Thesaurus. Code C2731.

A synthetic heterocyclic pyridinium compound. MKT -077 is a water soluble lipophilic cationic molecule and an analog of rhodacyanine dye, which partitions into tumor cell mitochondria where it is thought to act as a metabolic poison, leading to G1 arrest and apoptosis. This agent also shows selective cytotoxicity to cancer cells mediated by its binding to the hsp70 family protein mot-2 and reactivation of tumor suppressor p53 function. 